\title{
Chorea
}

\author{
Harold L. Klawans
}

\begin{abstract}
A variety of neurotransmitters have been implicated in the pathophysiology of chorea as exemplified by Huntington's chorea. These include dopamine, serotonin, acetylcholine, GABA and a variety of neuropeptides including substance $\mathrm{P}$ and somatostatin. Despite biochemical data that suggests that alterations in other neurotransmitters may be of greater significance, pharmacologic data still supports a major role of dopamine in the actual clinical manifestation of chorea.
\end{abstract}

RÉSUMÉ: La chorée. Plusieurs neurotransmetteurs ont été impliqués dans la pathophysiologie de la chorée, telle la chorée de Huntington. Parmi ceux-ci, signalons la dopamine, la sérotonine, l'acétylcholine, le GABA et plusieurs neuropeptides incluant la substance $P$ et la somatostatine. En dépit des données biochimiques qui suggèrent que des altérations d'autres neurotransmetteurs pourraient être plus importantes, les données pharmacologiques sont encore en faveur d'un rôle majeur pour la dopamine dans les manifestations cliniques de la chorée.

Can. J. Neurol. Sci. 1987; 14:536-540

Chorea neither defines nor implies any specific alteration in muscle tone but instead describes a specific class of abnormal involuntary movements. Chorea has been defined by the ad hoc Committee on Classification of the World Federation of Neurology as "a state of excessive, spontaneous movements, irregularly timed, non-repetitive, randomly distributed and abrupt in character.' These movements may vary in severity from restlessness with mild intermittent exaggeration of gesture and expression, fidgeting movements of the hands, unstable dancelike gait to a continuous flow of disabling, violent movements." Choreatic movements are considered to be both clinically and pathophysiologically similar in the wide diversity of disease states in which they may appear.

The choreatic syndrome that has the most clearly defined neuropathologic changes is Huntington's chorea. This paper will therefore focus on the possible pathophysiology of the symptoms of this disorder.

In Huntington's chorea, the major pathologic features are limited to the corpus striatum and cerebral cortex. Striatal atrophy is the most striking change. Although there is particular involvement of the small neurons of the caudate nucleus, it is not unusual to see degeneration in the large caudate neurons as well. Associated with this marked neuronal loss is extensive proliferation of astrocytes. The other striking pathologic feature is diffuse cerebral atrophy. This takes the form of a general reduction in the cortical population, with particularly heavy cell loss in layers 3,5 , and 6 . It is generally accepted that the choreiform movements of Huntington's disease (HD) are related to striatal pathology and that the mental changes are related to cortical pathology. ${ }^{2.3}$
In the past, it had been proposed that the striatum functions in part as a filter device for the control of motor activity. Degeneration of the striatum would thus result in the loss of this filter mechanism and produce chorea. According to this theory, as the degeneration of the striatum progressed, one would expect the abnormal involuntary movements to increase proportionally.

Several clinical observations show this to be untrue. First, patients in the terminal phase of Huntington's chorea often manifest less choreatic restlessness than they manifested earlier in the illness. Many patients reach a so-called burned out phase of the illness in which they actually become rigid and akinetic with virtually no abnormal involuntary movements at all. Since the later stages of the disease presumably would coincide with the time of greatest striatal destruction, one would expect the chorea to progress with time if chorea were directly correlated with tissue destruction. A second clinical observation is that some patients who have died in the early stages of Huntington's disease, with marked generalized chorea, have shown no gross changes within the striatum. In fact, even microscopic examination of the striatum sometimes revealed only minimal degenerative changes. In addition, radiologic attempts to correlate the degree of chorea with the degree of striatal atrophy have failed. Because of such observation, it is obvious that the degree of striatal cell loss cannot be accurately related to the degree of chorea observed in Huntington's disease. In the early seventies, I proposed that chorea was not due to the loss of function of dead striatal neurons, but instead was due to the dysfunction of diseased but surviving striatal neurons. ${ }^{2.3}$ This dysfunction was felt to involve the way in which striatal 
neurons responded to various neurotransmitters acting upon their membrane receptors.

\section{Dopaminergic Mechanism}

The first neurotransmitter to be implicated in the pathophysiology of chorea was dopamine (DA). In Huntington's chorea, the neurons of the striatum that normally receive the dopamine input from the substantia nigra are the major site of pathologic changes, but the dopamine content of the striatum is normal or near normal. ${ }^{4}$ This is in some ways the opposite of parkinsonism, in which the dopamine input to the striatum is abnormal, whereas the cells of the striatum are well preserved. In Huntington's disease, the dopamine input is normal, whereas the striatal cells are abnormal.

If chorea results from altered responsiveness or dysfunction of diseased striatal neurons to normal dopamine concentrations within the striatum, then pharmacologic agents that alter either the concentration of dopamine within the striatum or the ease of access of dopamine in reaching striatal dopamine receptors might conceivably alter the abnormal involuntary movements. Historically, the first agent reported to be of use in the treatment of chorea was reserpine. Reserpine is a rauwolfia alkaloid that is known to deplete the CNS of dopamine. The observation that reserpine both improves chorea and depletes cerebral dopamine is consistent with the concept that altering striatal dopamine concentration affects chorea. Reserpine exerts its pharmacologic effect by blocking the reuptake of biogenic amines into storage granules, so that it produces depletion of serotonin and norepinephrine, as well as dopamine, in the CNS (see Table 1). Under such circumstances it is not possible to make a definitive statement regarding which of these three biologically active agents, when decreased in concentration within the striatum, is responsible for the reserpine-induced decrease in chorea. Tetrabenazine, which has a similar mechanism of action, has similar efficacy.

The most widely studied agents in Huntington's chorea, aside from reserpine, are the neuroleptics. Of these, haloperidol is now used most extensively. Reduction of chorea with various neuroleptics has been reported frequently.

The basis of the central activity of neuroleptics is thought to be related to blocking of dopamine receptors. ${ }^{5}$ Although these agents have some effect in blocking acetylcholine and norepinephrine peripherally, the blockade of central dopamine receptors is accepted to be of primary importance in explaining the central activity of these agents. Whereas the effectiveness of reserpine in alleviating chorea could be related to serotonin, norepinephrine, or dopamine, the effectiveness of chlorproma-

Table 1: Pharmacology of chorea in Huntington's chorea

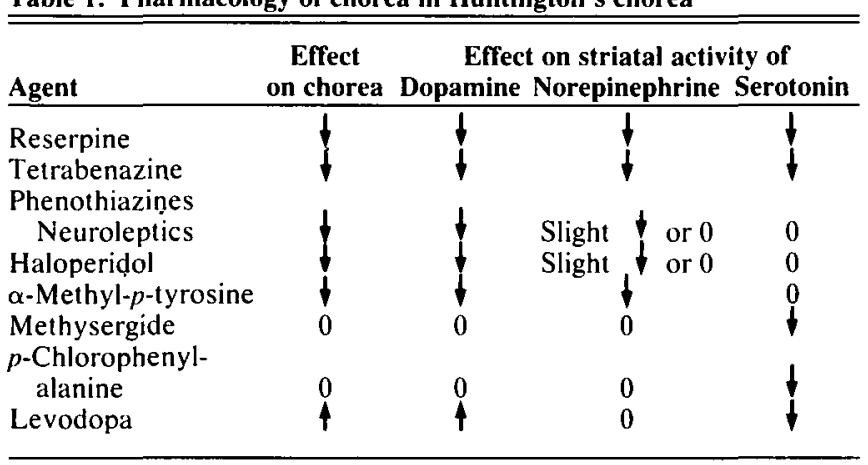

zine could be related only to dopamine. This suggests that dopaminergic mechanisms might well be of primary importance in the initiation of such movements.

Another method of altering the activity of striatal dopamine is the use of a-methyl-p-tyrosine. This agent is an inhibitor of tyrosine hydroxylase. The administration of a-methyl-p-tyrosine to animals results in decreased striatal levels of dopamine and norepinephrine without a change in the striatal concentration of serotonin. Birkmayer has reported that intravenous use of a-methyl-p-tyrosine in patients with Huntington's chorea results in amelioration of the choreiform movements. ${ }^{6}$ The effectiveness of a-methyl-p-tyrosine in chorea cannot be related to the influence of striatal serotonin since serotonin remains unaffected by this agent. Methysergide, which blocks serotonin receptors, and p-chlorophenylalanine, which blocks serotonin synthesis, have both been shown to have no effect on chorea. ${ }^{3}$

Taken together, these results suggest that dopamine is of primary importance in the initiation of chorea. Blocking the action of dopamine at the striatal receptors or decreasing the striatal content of dopamine improves chorea despite the fact that the striatal dopamine content is normal in this disease. These observations support the hypothesis that the defect producing chorea may involve dysfunction of the striatal neuron in its response to normal concentrations of dopamine.

Since drugs that decrease the striatal content of dopamine improve chorea, increasing the amount of dopamine that reaches the same receptors should worsen chorea. Levodopa markedly increases the striatal concentration of dopamine, has little effect on the striatal level of norepinephrine, and decreases the cerebral concentration of serotonin. Since levodopa increases striatal dopamine levels, it may increase the amount of dopamine reaching the receptors and thereby heighten chorea. It is fairly clear that long-term oral levodopa usually increases the hyperkinesia in Huntington's chorea. ${ }^{7}$

A study of the patient population at risk for Huntington's disease provides further support for the hypothesis that altered striatal neurons responding in an abnormal manner to dopamine result in the production of chorea. It seems a reasonable assumption that in the course of a progressive degenerative disease such as Huntington's chorea, even the most subtle abnormal involuntary movements ought to be preceded by a stage of the disease in which striatal degeneration has begun but there is not overt clinical manifestation. In other words, there may be a preclinical stage of Huntington's disease in which the patient is normal clinically but in which the disease process has already begun within the striatum. If altered responsiveness to dopamine causes chorea, and if this altered responsiveness is an early manifestation of the pathology of chorea, then it might be possible to bring out chorea in presymptomatic Huntington's patients before it would otherwise be evident by means of a trial of levodopa. This hypothesis assumes that levodopa does not induce chorea in normal persons and that in asymptomatic family members two populations can be identified: those in whom levodopa produces chorea and those in whom it does not. Presumably the former would be presymptomatic patients, whereas the latter would be either normal siblings or patients with potential abnormal striatal cells that were not altered sufficiently to respond abnormally to levodopa at the time of administration.

The major levodopa provocation study involved a multicenter investigation of 30 subjects, each at $50 \%$ risk of developing 
Huntington's chorea and 25 control subjects. ${ }^{8}$ Levodopa was administered orally, and all subjects were examined serially for the appearance of choreic movements. One-third of subjects at risk developed transient and fully reversible chorea while receiving levodopa, whereas no control subject developed abnormal movements. The investigation clearly demonstrated that some subjects at risk have enhanced sensitivity to dopaminergic stimulation. Because of this altered sensitivity, the investigators suggested that this group of patients may carry an increased risk of developing Huntington's disease. The investigators stressed that those subjects at risk who developed no chorea on levodopa provocation should not be considered likely "escapees," since they may well still carry the gene but not have developed sufficient dopaminergic hypersensitivity to respond abnormally to the administered dose of levodopa. Eight year follow-up data on these patients is presented in Table 2 and demonstrates a clear prognostic difference between the two patient groups. ${ }^{9}$ Statistically, the hypothesis that those patients who developed levodopa-related chorea may be at a higher risk for eventual HD appears true. The degree of predictive reliability for this test can only be determined with longer follow-up.

\section{Cholinergic Mechanisms}

The concept that a critical striatal balance between acetylcholine and dopamine is essential to normal striatal function and consequently to normal motor control initially received its greatest acceptance in its applicability to Parkinson's disease. The signs of parkinsonism are widely accepted as resulting from imbalance in the dopamine-acetylcholine relationship within the striatum as a result of the loss of striatal dopamine and a consequent imbalance in favor of acetylcholine. The use of levodopa to restore striatal dopamine results in improvement in Parkinson's disease. Parkinsonism is also improved by a wide variety of agents that block the central activity of acetylcholineanticholinergic agents. This central antagonism of acetylcholine is thought to restore partially the balance between dopamine and acetylcholine.

It has been further demonstrated that the administration of physostigmine, a centrally active anticholinesterase, worsens parkinsonism. Physostigmine has a marked effect in increasing striatal acetylcholine concentration. Presumably, the exacerbation of parkinsonism produced by the administration of physostigmine is a result of further worsening of the imbalance between

Table 2: Effect of levodopa on subjects at risk for Huntington's chorea and controls

\begin{tabular}{|c|c|c|c|}
\hline \multirow[b]{2}{*}{ Subjects at risk } & \multicolumn{2}{|c|}{$\begin{array}{c}\text { Response to Levodopa in } \\
1972 \\
\end{array}$} & \multirow{2}{*}{$\begin{array}{c}\text { Current } \\
\text { diagnosis of } \\
\text { Huntington's } \\
\text { disease (1980) } \\
\end{array}$} \\
\hline & Chorea & No chorea & \\
\hline \multirow[t]{2}{*}{$9^{a}$} & 3 & & 1 \\
\hline & & 6 & 0 \\
\hline \multirow[t]{2}{*}{$21^{b}$} & 7 & & 4 \\
\hline & & 14 & 1 \\
\hline \multirow[t]{2}{*}{ Totals: } & 10 & & 5 \\
\hline & & 20 & 1 \\
\hline
\end{tabular}

Fisher Exact Test performed on the data indicates a significance value of $p-0.0088$.

"University of Montreal.

"Rush-Presbyterian-St. Luke's Medical Center and Ohio State University. dopamine and acetylcholine by increasing striatal acetylcholine concentration.

With this background, Klawans and Rubovits studied anticholinergic and cholinergic influences on the abnormal movements seen in Huntington's disease. ${ }^{10}$ They demonstrated that the intravenous administration of physostigmine could temporarily reduce chorea. On the other hand, the administration of the anticholinergic agent benztropine-induced worsening could be promptly and effectively overcome by the subsequent administration of physostigmine. The benztropine reversal of physostigmine could be annulled by a subsequent second administration of physostigmine. It was postulated that the alteration in cholinergic mechanisms probably affects striatal neuronal function and thereby influences the chorea. Other workers have found that physostigmine improves chorea but the percentage of patients who respond varies from 20 to $80 \%$. These observations have two implications. Anticholinergic agents should be avoided in Huntington's disease patients being treated with neuroleptics since these agents will worsen the chorea. It is also possible that cholinergic agents might sometimes prove to be of value in the treatment of chorea. The acetylcholine precursors choline and lecithin have been used but with very limited efficacy."

It is important to note that recent biochemical studies have shown decreased activity of choline acetylase $(\mathrm{ChAc})$ in the basal ganglia of patients dying of Huntington's chorea. It is unlikely that this is the primary defect in such patients, as it seems to be more severe late in the disease..$^{7.12 .13}$ Loss of the ability to synthesize acetylcholine because of decreased $\mathrm{ChAc}$ activity in some patients may explain the variability of responsiveness to physostigmine. Hiley and Bird reported a marked reduction of muscarinic cholinergic receptor sites in the striatum of Huntington's chorea. ${ }^{14}$ The cholinergic components in the striatum almost exclusively belong to the cholinergic interneurones, and these interneurones are affected in Huntington's chorea. Physostigmine and oral choline have little ${ }^{10.15}$ or no beneficial effect ${ }^{11.16 .17}$ on choreic movements, suggesting that the loss of cholinergic receptors may be more important than any loss of ChAc.

\section{Serotonergic Mechanism}

The role of serotonin (5-hydroxytryptamine) in choreiform movements is less clear than the role of either dopamine or acetylcholine. The striatum has a relatively high concentration of serotonin, presumably as a result of the many serotonincontaining nerve terminals that synapse in this region. Since the striatum is the region of severe degeneration in Huntington's disease, the possible influence of serotonin on the abnormal involuntary movements seen in this syndrome has been investigated. It has been demonstrated that the administration of 5-hydroxytryptophan, the immediate metabolic precursor of serotonin, results in an exacerbation of the choreiform movements.

If increased serotonin activity exacerbates chorea, it might be possible to ameliorate chorea either by reducing CNS serotonin concentrations or by blocking serotonin activity. Orally administered methysergide, a centrally active serotonin blocking agent, for 1 to 2 months, failed to alter significantly the abnormal involuntary movements. ${ }^{3}$ Parachlorophenylalanine, which inhibits the hydroxylation of tryptophan to 5-hydroxytryptophan, results in a marked fall in CNS serotonin concentration without significantly affecting the metabolism of the 
catecholamines. This agent has no significant effect on the degree of the choreiform movements. ${ }^{18}$ The failure of a centrally active serotonin antagonist to improve chorea, in addition to the failure of a reduction in brain serotonin to improve chorea, suggests that the contribution of serotonin to the pathophysiology of chorea is limited at best.

\section{GABAergic Mechanisms}

A fourth putative neurotransmitter, GABA, has recently been proposed as having an influence in Huntington's chorea. Studies of regional CNS concentration have demonstrated a deficiency in GABA in the substantia nigra, putamen, caudate, and globus pallidus in patients with Huntington's disease as compared to "control" brains. ${ }^{19}$

In more recent studies it was shown that the major enzyme involved in the biosynthesis of GABA, glutamic acid decarboxylase (GAD), was reduced by approximately $75 \%$ in the basal ganglia of patients dying with Huntington's chorea. ${ }^{4.13}$ The concentrations were normal in the frontal cortex. Overall, the most consistent biochemical lesion in Huntington's chorea appears to be a loss of GABA synthesizing and containing neurons from the basal ganglia. It has been proposed that the reduced GABA concentration could be explained as being the result of genetically determined decreased activity of GAD or the result of the loss of a neuronal population that synthesizes GABA as a neurotransmitter.

It is important to note that one patient with Huntington's chorea who had only mild symptomatology when he committed suicide has been studied biochemically. Enzymatic analysis of this patient's striatum revealed normal activities of the pertinent enzymes. The particular finding that GAD activity was normal suggests that there is not a specific alteration in this enzyme characteristic of Huntington's chorea.

The significance of reduced GABA concentrations in the caudate, putamen, substantia nigra, and globus pallidus in Huntington's chorea remains unknown. The finding of a decreased concentration of a neurotransmitter in the striatum in choreatic patients, when viewed from a background of parkinsonism, is of course very seductive. In parkinsonism there is a loss of dopamine, and replacement of dopamine activity by precursor load (levodopa), reuptake blockade (amantadine), or directacting agonists (bromocriptine) improves parkinsonism. By analogy, increased GABA activity might ameliorate chorea. Unfortunately this has yet to be definitely demonstrated. A variety of pharmacologic techniques have been employed in this attempt, including:

(a) Precursor load strategy with 1-glutamate and pyridoxine. A 2-year trial has shown no therapeutic benefit. ${ }^{20}$

(b) Treatment with gamma-hydroxybutarate has not been successful.

(c) Possible agonism with baclofen has similarly shown no efficacy. ${ }^{21}$

(d) Agonism with muscimol, a direct-acting GABA agonist, has yet to produce significant improvement.

(e) Dipropylacetic acid inhibits GABA transaminase and thereby increases brain GABA levels. It has not been found to improve chorea, however. ${ }^{22}$

(f) It has been recently suggested that isoniazid given with pyridoxine will inhibit the breakdown of GABA by blocking GABA transaminase and result in increased brain $G A B A$ level. One report of 6 patients who were given this regime chronically found that 1 patient was markedly improved and 2 others less, but still significantly improved. ${ }^{23.24}$

(g) Aminoxyacetic acid, ${ }^{25} \gamma$-acetylenic-GABA ${ }^{26}$ and vinyl-GABA ${ }^{27}$ have also not proven to be useful.

None of these approaches has yielded reproducible amelioration or prevention of progression. These results, while unfortunate, suggest that the mere demonstration of a biochemical neurotransmitter deficit does not prove that this alteration is of physiologic or pharmacologic significance.

\section{Substance P}

Substance $\mathrm{P}$ has been shown to be markedly decreased in the substantia nigra ${ }^{28}$ in the internal segment of the globus pallidus. Substance $P$ is an excitatory of the striato nigral neurotransmitter and the striato-entopeduncular (internal pallidum) pathway and the decrease of substance $P$ in Huntington's chorea is considered to be the result of the degeneration of long-axoned substance-P-containing small or medium-sized striatal neurones. ${ }^{29}$ However, biochemical analysis of Huntington's chorea patients revealed that concentrations of substance $P$ in the substantia nigra and the internal pallidum were not strictly related to the presence or severity of chorea. ${ }^{30}$ It is very difficult to relate substance $P$ to the production of choreic movements.

\section{Somatostatin}

It has been shown that the concentration of somatostatin and the density of somatostatin-containing varicose fibers are both increased in Huntington's disease. ${ }^{31.32}$ Shults et al. recently completed a clinical trial with cysteamine which is a somatostatin depleting agent. ${ }^{33}$ Cysteamine was given for two weeks at maximally tolerated dosages which were sufficient to double growth hormone levels thereby suggesting a functionally significant decrease in central somatostatin levels. The treatment had no consistent effect on chorea.

\section{ACKNOWLEDGEMENTS}

This work was supported in part by the United Parkinson Foundation. Chicago, IL, and the Boothroyd Foundation, Chicago, IL.

\section{REFERENCES}

1. Lakke PWF. Classification of extrapyramidal disorders. J Neurol Sci 1981:51:311-327.

2. Klawans HL. A pharmacologic analysis of Huntington's chorea. Eur Neurol 1970: 4: 148-163.

3. Klawans HL. The Pharmacology of Extrapyramidal Movement Disorders. S. Karger, Basel, 1973.

4. Bird ED. Iversen LL. Huntington's chorea. Brain 1974;97:457-472.

5. van Rossum JM. The significance of dopamine receptor blockade for the action of neuroleptic drugs. In: Brill H. Cole JO. Deniker P, Hippius H, and Bradley PB eds., Neuro-Psychopharmacology. Proceedings of the 5th International Congress of the Collegium Internationale Neuropsychopharmacologicum. Washington. D.C., March, 1966. International Congress Series No. 1966: 129: 166.

6. Birkmayer W. The alpha-methyl-p-tyrosine effect in extrapyramidal disorders. Wien Klin Wochenschr 1969; 81: 10-12.

7. Klawans HL, Weiner WJ. The pharmacology of choreatic movement disorders. Prog Neurobiol 1975; 1-32.

8. Klawans HL, Paulson GW, Ringel SP, Barbeau A. Use of 1-dopa in the detection of presymptomatic Huntington's chorea. N Engl J Med 1972; 286: 1332-1334.

9. Klawans HL, Goetz CG, Perlik S. Presymptomatic and early detection in Huntington's disease. Ann Neurol 1980; 8: 343-347.

10. Klawans HL, Rubovits R. Central cholinergic-anticholinergic antagonism in Huntington's chorea. Neurology 1972: 22: 107-116. 
11. Aquilonius SM, Eckernas SA. Choline therapy in Huntington's chorea. Neurology 1977: 27: 887-889.

12. Aquilonius SM. On the synthesis, release and function of acetylcholine in the central nervous system. Ph.D. dissertation, Univeristy of Uppsala.

13. McGeer PL, McGeer EG. Fibiger HC. Choline acetylase and glutamic acid decarboxylase in Huntington's chorea. Neurology 1975; 23: 912-917

14. Hiley CR, Bird ED. Decreased muscarinic receptor concentration in post-mortem brain in Huntington's chorea. Brain Res 1974; 80: 355-355.

15. Aquilonius SM, Sjostrom R. Cholinergic and dopaminergic mechanisms in Huntington's chorea. Life Sci 1971; 10: 405-414.

16. Growdon JH, Cohen EL, Wurtman RJ. Huntington's disease: clinical and chemical effects of choline administration. Ann Neurol 1977; 1: 418-422.

17. Tarsy D. Leopold N, Sax DS. Physostigmine in choreiform movement disorders. Neurology 1974; 24: 28-33.

18. Chase TN, Watanabe AM, Brodie HKH, Donnelly EF. Huntington's chorea: Effect of serotonin depletion. Arch Neurol 1972; 26: 282-284.

19. Perry T, Hansen S. Kloster M. Huntington's chorea: Deficiency of gamma amino butyric acid. New Engl J Med 1973; 288: 337-342.

20. Barr AN, Heinze W, Mendoza JE, Perlik S. Long term treatment of Huntington's disease with 1-glutamate and pyridoxine. Neurology 1978; 18: 1280-1282.

21. Shoulson I, Chase TN, Roberts E. Huntington's disease treatment with imidazole-4-acetic acid. N Engl J Med 1975; 293: 504-505.

22. Shoulson I, Kartzinel R, Chase TN. Huntington's disease: Treatment with dipropylacetic acid and GABA. Neurology 1976: 26 : 61-63.

23. Perry T, Wright J, Hansen S, Macleod P. Isoniazid therapy of Huntington's disease. Neurology 1979; 29: 370-375.
24. Perry TL Wright JM, Hansen S, et al. A double-blind clinical trial of isoniazid in Huntington's disease. Neurology 1982;32:354-358.

25. Perry TL, Wright JM, Hansen S, et al. Failure of aminoxyacetic acid therapy in Huntington's disease. Neurology 1980; 30: 772-775.

26. Tell G, Böhlen P, Schechter PJ, et al. Treatment of Huntington's disease with -acetylenic GABA, an irreversible inhibitor of GABAtransminase: increased CSF GABA and homocarnosine without clinical amelioration. Neurology 1981; 31: 207-211.

27. Scigliano G, Giavannini P, Girotti $F$, et al. Gamma-vinyl GABA treatment of Huntington's disease. Neurology 1984; 34: 94-96.

28. Kanazawa I, Bird ED, O'Connell R, Powell D. Evidence for a decrease in substance $P$ content of substantia nigra in Huntington's chorea. Brain Res 1977; 120: 387-392.

29. Kanazawa 1, Bird ED, Gale JS, et al. Substance P: decrease in substantia nigra and globus paliidus in Huntington's disease. In. Chase TN, Wexler NS, Barbeau A (eds.), Advances in Neurology, Vol 23, Huntington's Disease, New York, Raven Press, 1979, 495-504.

30. Kanazawa I. Clinical pathophysiology of basal ganglia disease. In. Winken PJ, Bruyn GW, Klawans HL (eds.), Handbook of Clinical Neurology, in press.

31. Aronin N, Cooper PR, Lorens LF, et al. Somatostatin is increased in the basal ganglia in Huntington's disease. Ann Neurol 1983; 13: $519-526$

32. Marshall PE, Landis DM. Huntington's disease is accompanied by changes in the distribution of somatostatin-containing neuronal processes. Brain Res 1985; 329: 71-82.

33. Shults $C$, Steardo L, Barone $P$, et al. Huntington's disease: Effect of cysteamine, a somatostatin-depleting agent. Neurology 1986; 36: 1099-1102. 